Savahl, S. et al. (2013). An exploration into the impact of exposure to community violence and hope on children's perceptions of well-being: a South African perspective. Child Indicators

\title{
An exploration into the impact of exposure to community violence and hope on children's perceptions of well-being: a South African perspective
}

Shazly Savahl, Serena Isaacs, Sabirah Adams, Cassandra Zeta Carels and Rose September

\begin{abstract}
The study aims to explore the relationship between exposure to community violence, hope, and well-being. More specifically, the study aims to ascertain whether hope is a stronger predictor of well-being than exposure to violence. Stratified random sampling was used to select a sample of 566 adolescents aged 14-17 years, from both high violence and low violence areas in Cape Town, South Africa. A questionnaire consisting of Snyder's Children's Hope Scale, the Recent Exposure to Violence Scale and the KIDSCREEN-52 was used. Data analysis techniques included descriptive statistics, correlations, and multiple regression. A positive, significant relationship was found between children's hope and their well-being. Although exposure to community violence was found to be significantly correlated with well-being, the relationship was negligible. While exposure to community violence and hope were found to be significant predictors of well-being, hope emerged as a stronger predictor of child well-being than exposure to community violence.
\end{abstract}

\section{Exposure to Violence and Well-Being}

South Africa's socio-political history has created a society characterised by political struggles and various forms of violence. While the advent of democracy in 1994 led to a decrease in politically motivated violence, other forms of violence such as interpersonal, domestic and community violence are still endemic in post Apartheid South Africa. Of great concern is the impact that these forms of violence are having on the children and youth of South Africa who are exposed to violence on a daily basis (Isaacs et al. 2011). Exposure to violence, in any of its various manifestations, has shown to be one of the most damaging experiences a child can endure (Buckner et al. 2004; Isaacs 2010), with substantial evidence indicating a range of negative psychosocial outcomes (Muller et al. 2000; Henrich et al. 2004; Raviv et al. 1999; Schwartz and Proctor 2000). Community violence, in particular, has been identified in local and international research as critically impacting on child and adolescent well-being.

Community violence, defined by McCart et al. (2007 p. 434) as "deliberate acts intended to cause physical harm against a person in the community,", also includes gang violence, violence in the home, school and other public spaces. In this research study, 
exposure to community violence is utilised in reference to those experiences which involve violent events that are either indirect (heard of or witnessed), or direct (such as experiences of victimisation) (Brady et al. 2008). Furthermore, communities in South Africa are generally diverse entities characterised by socio-economic disparities, and thus there is a significant difference in levels of exposure to violence across communities and perceptions of well-being. Cape Town, identified as one of South Africa's 'crime hotspots' (City of Cape Town 2009), typifies the above contention with different communities affected by varying degrees of violence. This study focused on the impact that exposure to community violence has on adolescents' subjective well-being in various communities within the Cape Town Metropole.

\section{Child Well-Being}

The concept of well-being has its genesis in Jahoda's (1958) theoretical proposal of positive psychological health and the concept of quality of life (see Cummins 1995). It is defined as "A state of successful performance throughout the life course integrating physical, cognitive, and socio-emotional function that results in productive activities deemed significant by one's cultural community, fulfilling social relationships, and the ability to transcend moderate psychosocial and environmental problems" (Pollard and Rosenberg 2003 p. 14). This denotation accentuates the multi-dimensional nature of the well-being construct which encompasses several domains, namely physical, psychological, social, cognitive, educational and economic (Pollard and Lee 2003). Therefore, as a complex multi-dimensional construct, there are a range of factors that could have possible adverse effects on well-being (September and Savahl 2009). The present study has identified exposure to violence as one of these potentially harmful factors which could negatively impact on child well-being across all the domains.

While there is a substantial body of empirical research confirming the adverse effects of exposure to community violence on well-being (see Chen and Astor 2009; Isaacs et al. 2011; Margolin and Gordis 2000; Rosario et al. 2007), evidence indicating a range of protective factors has also emerged. These include familial structural characteristics (family cohesion and quality of relationships between family members, stable secure living arrangements, traditional social processes, and positive parenting processes), quality of relationship with peers, self-esteem, a well-developed value system, resilience, and hope (Isaacs et al. 2011; Oskin 1996; Salzinger et al. 2002). The construct of hope in particular, has emerged in recent literature as a key protective factor and positive indicator of well-being. In a previous edition of Child Indicators Research, 4 (3), Merkaš and Brajša-Žganec (2011 p. 500) identify hope as "a positive indicator of child's development and as a psychological strength in relation to individual characteristics (life satisfaction and self-esteem) and social-environmental characteristics (family cohesion and perceived social support)." Others (e.g. Gilman et al. 2006; Isaacs 2010; September and Savahl 2009) have identified hope as a significant dimension of wellbeing.

Snyder (2002) presents an argument for the theory of hope, asserting that it may assist in reducing many risks by acting as a protective factor for individuals against despair or hopelessness. He conceptualises hope as a cognitive process used in establishing and achieving goals and ascertaining individuals' sense of future. Furthermore, it is an 
active and useful tool in overcoming traumatic and challenging events in childhood, such as violence, ultimately contributing toward a greater sense of well-being. In theory, the higher the levels of hope in an individual, the higher the levels of well-being, regardless of contextual realities such as exposure to endemic violence. Hope is also often considered as a key component of resilience. The concept of resilience is related to maintaining normal functioning or surpassing expectations, subsequent to an adverse experience occurring (Ungar and Perry 2012). Numerous factors impact upon an individual's ability to cope with these adverse experiences, varying from the biological, psychological, interpersonal, and socio-cultural (Ungar and Perry 2012).

\section{The Context of Community Violence in South Africa}

Violence and crime committed against children remains a pervasive challenge within South Africa (United Nations Children's Fund (UNICEF) 2009). In South Africa between 2008 and 2009, approximately 50,000 children were victims of violent crimes (South African Police Services 2009). This figure increased to 56,500 children being victims of crime between 2009 and 2010 (UNICEF 2009). Individuals 19 years and younger accounted for $10 \%$ of all deaths in 2009, of which the predominant amount was clustered in the 15-19 year age category (National Injury Mortality Surveillance System 2010). The majority of crimes against children however, are evident in the $15^{-17}$ year cohort. Within this group, murder accounts for $54.90 \%$ of violence against children, attempted murder $59.60 \%$, assault with the intent of grievous bodily harm (GBH) $70.80 \%$, common assault $63.10 \%$ and sexual offences $39.50 \%$ (South African Police Service 2010). Nineteen percent of violent crimes were committed against children aged o-10 years, with murder representing $7.00 \%$, attempted murder $22.50 \%$, assault with the intent of GBH $9.90 \%$, common assault $11.20 \%$, and sexual offences $29,40 \%$ (South African Police Service 2010). Child sexual abuse in SA is the most pertinent form of violence against children (South African Police Service 2010), affecting $29 \%$ of all children between the ages of $\mathrm{o}$ and 10 years (UNICEF 2009). In terms of Cape Town in particular, it has been reported that amongst a population of 3.4 million, the murder rate has been reported to be 60 deaths per 100,000 per year (City of Cape Town 2007). More so, rape statistics have revealed that 73 rapes occur per 100,000 per year (City of Cape Town 2007). Additionally, drug-related crime indicates an incidence rate of 830 per 100,000 per year (City of Cape Town 2007).

\section{Exposure to Violence, Hope and its Effects on Well-Being}

Farver et al. (2000) investigated how children's perceptions of neighbourhood violence and safety were related to their socio-emotional functioning, neighbourhood violent crime rates, and parent ratings of neighbourhood safety and violence. They found that when children are exposed to violence, their well-being, sense of self, and opportunities to play safely within their environments is compromised. Those from high violence areas showed more violent content in their drawings than those from low violence areas. Children who perceived their neighbourhoods as unsafe felt that they could not play outdoors, were suspicious of the police, and had a lower perceived self-competence and an external locus of control. Farver et al. (2000) conclude that exposure to community violence negatively affects children's well-being. 
Moreover, a considerable amount of research (Boney-McCoy and Finkelhor 1995, 1996; Elze et al. 1999; Freeman et al. 1993; Gorman-Smith and Tolan 1998; Juvonen 2000; Pastore et al. 1996; Schwab-Stone et al. 1995, 1999; Singer et al. 1995) has shown an association between exposure to community violence and its effects both on internalising and externalising behaviour problems and symptomatology. A range of internalising effects to this exposure were found, such as depressed mood, (Boney-McCoy and Finkelhor 1995, 1996; Freeman et al. 1993; Gorman-Smith and Tolan 1998; Schwab-Stone et al. 1995, 1999; Singer et al. 1995), anxiety (Boney-McCoy and Finkelhor 1995; Freeman et al 1993; Hill et al. 1996), somatization (Schwab-Stone et al. 1995, 1999), post-traumatic stress disorder (PTSD) (McCart et al. 2007; Singer et al. 1995), low self-esteem (BoneyMcCoy and Finkelhor 1995; Lynch and Cicchetti 1998), loneliness (Juvonen et al. 2000), suicidality (Elze et al. 1999; Pastore et al. 1996), physiological adaptation (such as sleep disturbance and low resting pulse), and emotional desensitization (Cooley-Quille and Lorion 1999). In contrast, externalising effects of exposure to community violence were found to be associated with violent behaviour (Farrell and Bruce 1997), self-identification with a high-risk group (Sussman et al. 1999), offensive and defensive fighting (Jenkins and Bell 1994), gang fighting (DuRant et al. 1994), school-related problems (such as suspensions and school complaints to parents) (Bowen and Bowen 1999), conduct disorder (Elze et al. 1999), antisocial behaviour (Miller et al. 1999), and substance abuse or dependence (Jenkins and Bell 1994; Fick and Thomas 1995). Considering the extensive range of empirical research detailing internalising and externalising problems, researchers (see e.g., McCart et al. 2007) have suggested that future research should shift their focus to explore factors which could serve to buffer the negative effects of violence. Within the current research study, hope is seen as one of those buffers.

The importance of hope was highlighted in a quantitative study by Gilman et al. (2006) who investigated the relationship between adolescent students' level of hope and various well-being indicators, such as academic and psychological aspects of school adjustment. They found that youth who reported low levels of hope also reported significantly high levels of maladaptive indicators, such as irregular school attendance, maladaptive behaviour and dropping out of school, and poor academic achievement. Also, adolescents possessing high levels of hope reported greater positive benefits and also scored high on personal adjustment and global life satisfaction. Gilman et al. (2006) believe that high hope is necessary because it is linked to a number of positive psychological outcomes.

Similar research with regard to hope and its relationship to positive psychological outcomes and various dimensions of well-being have been conducted by Merkaš and Brajša-Žganec (2011) and Edward et al. (2007). Merkaš and Brajša-Žganec (2011) found that higher levels of children's hope are associated with higher levels of life satisfaction, selfesteem, social support, and family cohesion, whilst Edward et al. (2007) found hope to be positively associated with life satisfaction, social support and optimism.

With specific reference to the current study, Oskin (1996) investigated the relationship between community violence and hope in children living in a low-income community with high violence rates. She found a significant negative relationship between community violence exposure and hope; as community violence increased, hope 
decreased. Oskin (1996) recommends that subsequent research should focus on identifying factors which increase children's hope.

\section{Aim of the Study}

The study aims to explore the relationship between exposure to community violence, hope, and perceptions of well-being. More specifically, the study aims to ascertain whether hope is a stronger predictor of perceptions of well-being than exposure to violence. The following hypotheses have been developed to guide the study:

Hypothesis 1: There is a significant relationship between children's exposure to community violence and their perceptions of well-being.

Hypothesis 2: There is a significant relationship between children's sense of hope and their perceptions of well-being.

Hypothesis 3: Exposure to community violence and children's sense of hope are significant predictors of perceptions of well-being

Hypothesis 4: Hope is a stronger predictor of well-being than exposure to community violence.

\section{Method}

\subsection{Participants}

South Africa in general, and Cape Town in particular, is characterised by high levels of social inequality which has resulted in the stark division between the rich and poor. This has manifested in the polarisation of communities and neighbourhoods into privileged or high socio-economic and disadvantaged or low socio-economic. Privileged communities are characterised by high income, high educational attainment, high levels of employment, and low incidence of violence (City of Cape Town 2006). Disadvantaged communities are characterised by low educational attainment and income, high rates of substance abuse, unemployment, and crime and violence. Due to the pervasiveness of these social inequalities, the sampling frame consisting of both privileged (low violence) and disadvantaged (high violence) communities was established. The sample consisted of 566 adolescents from seven public schools within the Education Management and Development Centre (EMDC) South Metropole of the Western Cape Education Department. The WCED has four urban education districts, namely EMDC North, East, Central, and South. The EMDC South district in particular is characterised by both high and low violence communities, and was chosen owing to the high number of key nodal areas within that district. Key nodal areas are severely impoverished regions which have been identified by national government as requiring focused intervention. Stratified random sampling was used to divide the population into two strata (high violence and low violence). Thereafter, the participating schools were selected from each stratum using simple random sampling, and the sub-samples were then collated to form the total sample. This type of sampling is used for efficiency and comparability (Judd et al. 1991).

Participants in mid-adolescence (14-15 years) were initially selected based on the assumption that they would be a typical representation of the adolescent developmental stage. To this end, the researchers requested the participation of all grade nine students of the selected schools, as most grade nine students fall within the required age cohort. 
However, the final sample consisted of 218 male and 348 female students between the ages of $13-17$, with the majority being 15 years old, and a mean age of 15.04 .

\subsection{Data Collection Tools}

A self-report questionnaire, consisting of three standardised scales, was used to measure the constructs of hope, community violence, and well-being. The questionnaire consisted of two sections. Section A contained questions on biographical information of participants, which included their age, home language, gender, and their place of residence; whilst Section B comprised of three scales, namely, the Children's Hope Scale, Recent Exposure to Violence Scale, and the Kidscreen-52.

The Children's Hope Scale developed by Snyder et al. (1997) was used to measure the construct of hope. The scale consists of six items, measuring Snyder's conceptual definition of hope, as explicated above. The odd-numbered items reflect agency and the even-numbered items reflect pathways to goals (Snyder et al. 1997). Cronbach's alpha for this scale is .77. Response options are presented on a six-point Likert scale, ranging from 'none of the time' (1) to 'all of the time' (6).

The Recent Exposure to Violence Scale (REVS) was used in order to assess adolescents' exposure to violence in their home, school, and neighbourhood. The 26item REVS (Singer et al. 1999) used in the current study to measure adolescents' exposure to violence in their community is an adapted version of the REVS 22-item scale (Singer et al. 1995). A four-point Likert scale ranging from never (1) to almost every day (4) was used (Singer et al. 1999). Cronbach's alpha for the 26-item scale are as follows: 1) witness of neighbourhood violence $(\alpha=0.80), 2)$ victim/witness of home violence $(\alpha=0.77), 3)$ witness of school violence $(\alpha=0.76), 4)$ victim/witness of a shooting or knife attack $(\alpha=0.75), 5)$ victim of school or neighbourhood violence $(\alpha=0.72)$ and 6$)$ sexual abuse $(\alpha=0.52)$. All Cronbach's alphas with the exception of sexual abuse are greater than 0.70, indicating an acceptable level of reliability (Singer et al. 1999). However, the mean for Cronbach's alpha on all 26 items is $\alpha=0.72$ which designates an acceptable value.

Ravens-Sieberer et al. (2008) report the first psychometric results of the European KIDSCREEN-52. This scale was used to measure child well-being across various dimensions, including physical, psychological, financial circumstances, selfperception, social acceptance as well as the school environment (Ravens-Sieberer et al. 2008). Various psychometric aspects were studied including feasibility, reliability as well as convergent and construct validity. The internal consistency of the KIDSCREEN52 was calculated using Cronbach's alpha and ranged between 0.77 and 0.89. Pearson correlation co-efficients were computed to analyse convergent validity between the Kidscreen-52 dimensions and the KINDL (a scale measuring similar constructs). Pearson correlation coefficient reported $r$ between 0.50 and 0.68 . The KIDSCREEN-52 was further assessed for validation for use in several European countries (Robitail et al. 2006), once again providing evidence for acceptable psychometric properties. The internal consistency of the KIDSCREEN-52, calculated using Cronbach's alpha, was over 0.70 indicating a coefficient acceptable for use. In terms of construct validity, item-scale correlations indicate a standard of .40 for each item. 
A reliability analysis was conducted in order to determine the Cronbach's alpha for the three relevant scales, namely, The Children's Hope Scale, Recent Exposure to Violence Scale and the KIDSCREEN-52 (see Table 1 below). All three scales showed an internal consistency between 0.70 and 0.95 which can be regarded as acceptable (Field 2009).

\subsection{Procedure}

Permission to conduct the study was obtained by the University of the Western Cape's (UWC) Research Ethics Committee, and the Western Cape Education Department (WCED). Information sessions were held with the principals from the selected schools to present information about the study. All the selected schools agreed to participate. Written informed consent was obtained from the principals of the schools, parents, and students. Questionnaires were administered by the research team in a classroom setting during a dedicated 30-min period. Completed questionnaires were assigned an identity number, coded according to the school and subsequently captured. Thereafter data was cleaned and screened for accuracy of data entry in preparation for data analysis.

\subsection{Data Analysis}

Data was analysed using the Statistical Package for the Social Sciences (SPSS). Univariate statistics were used for describing the demographics of the sample as well as the distributions of the independent (exposure to violence and hope) and dependent variables (perceptions of well being). The hypotheses were tested using Pearson's correlation and multiple regression statistical techniques.

Table 1 Reliability analysis

\begin{tabular}{llll}
\hline & Cronbach's alpha & $\begin{array}{l}\text { Cronbach's alpha on } \\
\text { standardized items }\end{array}$ & $\begin{array}{l}\text { No. of } \\
\text { items }\end{array}$ \\
\hline Hope Scale & 0.711 & 0.715 & 6 \\
REVS & 0.876 & 0.875 & 26 \\
KIDSCREEN & 0.923 & 0.918 & 52 \\
\hline
\end{tabular}

\subsection{Ethical Considerations}

The ethical guidelines stipulated by the UWC and of the WCED were strictly adhered to. Participants were fully informed of the nature of the study, its aims and objectives, and their anticipated role in this study. Voluntary and written informed consent was obtained by both participants and their parents. No personal identification details were requested on the questionnaire which ensured anonymity. Participants were further informed of their right to withdraw from the study at any point without consequence. The collected data was secured in a safe location and only accessed by members of the research team. Counselling services were made available to participants who may have experienced any trauma or difficulties relating to the topic.

\section{Results}


Hypothesis 1: There is a significant relationship between children's exposure to community violence and their perceptions of well-being.

Pearson correlation was conducted in order to determine the relationship between children's exposure to community violence and their perceptions of well-being. The results indicate a significant negative correlation $(r=-0.157 ; p<0.01)$. Therefore, an increase in exposure to violence leads to a decrease in well-being (see Table 2).

Hypothesis 1 is thus not rejected.

Hypothesis 2: There is a significant relationship between children's sense of hope and their perceptions of well-being

Pearson correlation was conducted in order to determine the relationship between children's sense of hope and their well-being. The results indicate that the there is a significant positive relationship between hope and well-being $(r=0.43 ; p<0.01)$ (See Table 3). Therefore hypothesis 2 is not rejected.

Hypothesis 3: Exposure to community violence and children's sense of hope are significant predictors of perceptions of well-being

Forced entry multiple regression, where predictor variables are forced into the model simultaneously, was used to test the second hypothesis of the study and is interpreted according to Field (2009). Utilising this technique statistical technique allows for the testing of the hypothesis that exposure to community violence and levels of hope will predict perceived well-being in adolescents (Field 2009). The dependent variable entered was children's perceptions of well-being, while the predictors were perceptions of hope and exposure to community violence. The overall model summary is presented in Tables 4 and 5 below.

Table 2 Correlations

\begin{tabular}{llll}
\hline & & Violence & Wellbeing \\
\hline Violence & Pearson Correlation & 1 & $-0.157^{* \bullet}$ \\
& Sig. (2-tailed) & & .000 \\
\multirow{5}{*}{ Wellbeing } & $\mathrm{N}$ & 553 & 450 \\
& Pearson Correlation & $-0.157^{* \bullet}$ & 1 \\
& Sig. (2-tailed) & .000 & \\
& $\mathrm{~N}$ & 450 & 459 \\
\hline
\end{tabular}

***orrelation is significant at the 0.01 level (2-tailed) 


\begin{tabular}{llll}
\hline & & Hope & Wellbeing \\
\hline Hope & Pearson Correlation & 1 & $.425^{* *}$ \\
& Sig. (2-tailed) & & .000 \\
\multirow{4}{*}{ Wellbeing } & $\mathrm{N}$ & 553 & 450 \\
& Pearson Correlation & $.425^{* *}$ & 1 \\
& Sig. (2-tailed) & .000 & \\
& $\mathrm{~N}$ & 450 & 459 \\
\hline
\end{tabular}

**Correlation is significant at the 0.01 level (2-tailed)

Table 4 Hope and community violence model summary

\begin{tabular}{lllll}
\hline Model & $\mathrm{R}$ & R Square & Adjusted R Square & Std. Error of the Estimate \\
\hline 1 & $.450^{\mathrm{a}}$ & .203 & .199 & 23.371 \\
\hline
\end{tabular}

Table 5 ANOVA

\begin{tabular}{lllccc}
\hline Model & Sum of Squares & df & Mean Square & F & Sig. \\
\hline 1 Regression & 61989.826 & 2 & 30994.913 & 56.748 & $.000^{\mathrm{a}}$ \\
Residual & 243600.410 & 446 & 546.189 & & \\
Total & 305590.236 & 448 & & & \\
\hline
\end{tabular}

Table 6 Coefficients

\begin{tabular}{lcccrrr}
\hline Model & \multicolumn{2}{l}{ Unstandardized Coefficients } & & Standardized Coefficients & $\mathrm{t}$ & Sig \\
\cline { 2 - 3 } & $\mathrm{B}$ & Std. Error & & Beta & & \\
\hline Constant & 157.470 & 7.554 & & -.151 & 20.845 & .000 \\
Violence & -.400 & .112 & .421 & -3.561 & .000 \\
Hope & 2.217 & .223 & & 9.951 & .000 \\
\hline
\end{tabular}


The overall model indicates the extent to which the predictors account for the change in the outcome variable (Table 4). This means that hope and exposure to community violence accounts for $20.30 \%$ of the variation in well-being.

Table 5 indicates the extent to which the model can be accounted for by chance, and points to the ability of the predictor variables to predict the outcome variable (Field 2009). This means that hope and exposure to community violence are significant predictors of wellbeing $(F=56.75 ; p<0.00)$. Therefore hypothesis 3 is not rejected.

Hypothesis 4: Hope is a stronger predictor of well-being than exposure to community violence

Both the predictors of hope $(t=9.95 ; p \leq 0.00)$ and exposure to violence $(t=-3.56 ; p \leq$ o.00) are significant predictors of well-being $(p<0.01)$. One predictor (hope) indicates a significant positive relationship and the other (exposure to community violence) a significant negative relationship.

Therefore, an increase in levels of hope leads to an increase in well-being, whilst an increase in exposure to community violence leads to a decrease in well-being. The results further show that children's perception of hope is a significantly stronger predictor of well-being than exposure to community violence (see Table 6). Therefore hypothesis 4 is not rejected.

\section{Discussion}

The overall aim of the study was to investigate the influence of hope and violence on children's well-being.

Key findings indicate a significant positive relationship between hope and well-being, and a significant negative relationship between exposure to violence and well-being. These findings are well corroborated in literature with Edward et al. (2007) Gilman et al. (2006) and Snyder et al. (1997; 2002), reporting hope as a significant correlate of adolescent well-being, whereas Brady et al. (2008), Farver et al. (2000) and Isaacs (1992) report that exposure to violence has a negative impact on adolescent well-being.

Whilst the above findings were anticipated, the regression modeltesting the combined relationship between exposure to violence and hope on adolescent well-being produced interesting results. The model summary (Table 4) indicated that children's sense of hope and exposure to violence only accounts for $20.30 \%$ of the variation in their perceptions of well-being. Even though the overall model of children's sense of hope and exposure to violence still presents as a statistical significant predictor of children's wellbeing, the effect is negligible, suggesting a range of other contributing factors which could account for the variation. Further factors may include perceived social support, adolescents' self-esteem, and other environmental factors.

A growing body of research (Lucas 2007; Lucas et al. 2004; Lucas 2005) has shown that the attenuation of emotional effects in response to a particular negative stimulus over time, such as continuous exposure to community violence which could result in 
desensitisation, may provide an additional explanation for this finding. This psychological process, known as hedonic adaptation, suggests that people have the capacity to completely adapt to certain negative experiences but show only protracted or partial adaptation to others (Lyubomirsky 2008). This is portrayed in research conducted by Funk et al. (2003), Isaacs et al. (2011), McCart et al. (2007), and Savahl (2010), who found that continuous exposure to violence could result in a blunting of psychological responses to violence.

A critical finding of the study was that hope emerged as a stronger predictor of wellbeing than violence. The construct of hope could, therefore, potentially interact to moderate the well-established inverse relationship between exposure to violence and well-being. However, the nature of this interaction would be dependent on how hope is conceptualised. Considering the distinction between robust and naive hope is important in this regard. Robust versions of hope are "rooted in a sense of reality" (Singh and Sawyer 2008, p.4), founded on the achievement of attainable goals by emphasising human agency, resilience, and sustainability (Sawyer et al. 2007), whilst naive hope is characterised by unrealistic optimism and a lack of understanding of the nature of the obstacles that could inhibit the attainment of goals (Sawyer et al. 2007; Singh and Sawyer 2008). The implication of this is that hope could be seen to play an important role as a protective factor against the adverse effects of community violence. This advances the notion of hope as an indicator of positive psychological outcomes and psychosocial well-being (Gilman et al. 2006; Merkaš and Brajša-Žganec

\section{Conclusion and Recommendations}

This study found that the construct of hope is a stronger predictor of well-being than exposure to community violence. This implies that strategic intervention initiatives should place emphasis on protective or resilience factors which could moderate the relationship between violence exposure and well-being, and ultimately contribute positively to child well-being. These include good role models and mentors, increase in social support and self-esteem, as well as access to and implementation of life skills educational programmes. It is recommended that future research should intensify investigation into various factors of resilience, specifically exploring how these factors relate and interact with one another and their potential to moderate or mediate the relationship between exposure to violence and well-being.

\section{Acknowledgments}

This research received financial support from the National Research Foundation of South Africa. 


\section{References}

Boney-McCoy, S., \& Finkelhor, D. (1995). Psychological sequelae of violent victimization in a national youth sample. Journal of Consulting and Clinical Psychology, 63, $726-736$.

Boney-McCoy, S., \& Finkelhor, D. (1996). Is youth victimization related to trauma and depression after controlling for prior symptoms and family relationships? A longitudinal, prospective study. Journal of Consulting and Clinical Psychology, 64, 1406-1416.

Bowen, N. K., \& Bowen, G. L. (1999). Effects of crime and violence in neighbourhoods and schools on the school behaviour and performance of adolescents. Journal of Adolescent Research, 14(3), 319-342.

Brady, S. S., Gorman-Smith, D., Henry, D. B., \& Tolan, P. H. (2008). Adaptive coping reduces the impact of community violence exposure on violent behavior among African American and Latino male adolescents. Journal of Abnormal Child Psychology, 36, 105-115.

Buckner, J. C., Beardslee, W. R., \& Bassuk, E. L. (2004). Exposure to violence and lowincome children's mental health: Direct, moderated, and mediated relations. The American Journal of Orthopsychiatry, 74(4), 413-423.

Chen, J. K., \& Astor, R. A. (2009). Students' reports of violence against teachers in Taiwanese schools. Journal of School Violence, 8(1), 2-17.

City of Cape Town (2006). Information and Knowledge Management Department, The Spatial Distribution of Socio-Economic Status, Service Levels and Levels of Living in the City of Cape Town 2001, Janet Gie and Philip Romanovsky.

City of Cape Town (2007). Crime in Cape Town: 2001-2006, Strategic Development Information and GIS Department, Janet Gie and Craig Haskins.

City of Cape Town (2009). Crime in Cape Town: 2001-2008, Strategic Development Information and GIS Department, Janet Gie.

Cooley-Quille, M., \& Lorion, R. (1999). Adolescents' exposure to community violence: sleep and psychophysiological functioning. Journal of Community Psychology, 27, 367-375.

Cummins, R. (1995). The comprehensive quality of life scale: Theory and development: Health outcomes and quality of life measurement. Canberra: Institute of Health and Welfare.

DuRant, R. H., Pendergrast, R. A., \& Cadenhead, C. (1994). Exposure to violence and victimization and fighting behavior by urban Black adolescents. Journal of Adolescent Health, 15, 311-318.

Edward, L. M., Ong, A. D., \& Lopez, S. J. (2007). Hope measurement in Mexican American youth. Hispanic Journal of Behavioral Sciences, 29(2), 225-241.

Elze, D. E., Stiffman, A. R., \& Dore, P. (1999). The association between types of violence exposure and youths' mental health problems. International Journal of Adolescent Medicine and Health, 11, 221-255.

Farrell, A. D., \& Bruce, S. E. (1997). Impact of exposure to community violence on violent behavior and emotional distress among urban adolescents. Journal of Clinical Child Psychology, 26, 2-14.

Farver, J. M., Ghosh, C., \& Garcia, C. (2000). Children's perceptions of their neighbourhoods. Journal of Applied Developmental Psychology, 21(2), 139-163. 
Fick, A. C., \& Thomas, S. M. (1995). Growing up in a violent environment: relationship to health-related beliefs and behaviors. Youth and Society, 27, 136-147.

Field, A. (2009). Discovering statistics using SPSS. Washington DC: Sage.

Freeman, L., Mokros, H., \& Poznanski, E. (1993). Violent events reported by normal urban school-aged children: characteristics and depression correlates. Journal of the American Academy of Child and Adolescent Psychiatry, 32, 419-423.

Funk, J. B., Elliott, R., Bechtoldt, H., Pasold, T., \& Tsavoussis, A. (2003). The attitudes towards violence scale: Child version. Journal of Interpersonal Violence, 18, 186196.

Gilman, R., Dooley, J., \& Florell, D. (2006). Relative levels of hope and their relationship with academic and psychological indicators among adolescents. Journal of Social and Clinical Psychology, 25(2), 166-178.

Gorman-Smith, D., \& Tolan, P. (1998). The role of exposure to community violence and developmental problems among inner-city youth. Development and Psychopathology, 10, 101-116.

Henrich, C. C., Schwab-Stone, Fanti, K., Jones, S. M., \& Ruchkin, V. (2004). The association of community violence exposure with middle-school achievement: a prospective study. Applied Developmental Psychology, 25, 327-348.

Hill, H. M., Levermore, M., Twaite, J., \& Jones, L. P. (1996). Exposure to community violence and social support as predictors of anxiety and social and emotional behavior among African American children. Journal of Child and Family Studies, $5,399-414$.

Isaacs, M., (1992). Impact of community violence on African American children and youth and families: Collaborative approaches to prevention and intervention, workshop summary. Arlington, VA: National Center for Education in Maternal and Child Health.

Isaacs, S. A. (2010). The influence of hope on children's perceptions of well-being in a disadvantaged community in Cape Town. Unpublished Master Thesis. University of the Western Cape. Bellville.

Isaacs, S. A., Savahl, S., Rule, C., Amos, T., Arendse, D., Lambert, C., et al. (2011). An investigation into the relationship between community violence exposure and adolescents' psychosocial well-being. The Social Work Practitioner-Researcher, 23(1), 57-78.

Jahoda, M. (1958). Current concepts of positive mental health. New York: Basic Books.

Jenkins, E. J., \& Bell, C. C. (1994). Violence among inner city high school students and post-traumatic stress disorder. In S. Friedman (Ed.), Anxiety disorders in African Americans (pp. 76-88). New York: Springer.

Judd, C. M., Smith, E. R., \& Kidder. (1991). Research methods in social relations. Fort Worth: Holt, Rinehart and Winston.

Juvonen, J., Nishina, A., \& Graham, S. (2000). Peer harassment, psychological adjustment, and school functioning in early adolescence. Journal of Educational Psychology, 92, 349-359.

Lucas, R. E. (2005). Time does not heal all wounds: a longitudinal study of reaction and adaptation to divorce. Psychological Science, 16, 945-950.

Lucas, R. (2007). Personality and subjective well-being. In M. Eid \& R. Larsen (Eds.), The science of subjective well-being. New York: Guilford Press. 
Lucas, R. E., Clark, A. E., Georgellis, Y., \& Diener, E. (2004). Unemployment alters the set point for life satisfaction. Psychological Science, 15, 8-13.

Lynch, M., \& Cicchetti, D. (1998). An ecological-transactional analysis of children and contexts: the longitudinal interplay among child maltreatment, community violence, and children's symptomatology. Development and Psychopathology, 10, $235-257$.

Lyubomirsky, S. (2008). The how of happiness: A scientific approach to getting the life you want. New York: Penguin Press.

Margolin, G., \& Gordis, E. B. (2000). The effects of family and community violence on children. Annual Review of Psychology, 51, 445-479.

McCart, M. R., Smith, D. W., Saunders, B. E., Kilpatrick, D. G., Resnick, H., \& Ruggiero, K. J. (2007). Do urban adolescents become desensitized to community violence? Data from a national survey. The American Journal of Orthopsychiatry, 77(3), 434-442.

Merkaš, M., \& Brajša-Žganec, A. (2011). Children with different levels of hope: Are there differences in their self-esteem, life satisfaction, social support, and family cohesion? Child Indicators Research, 4(3), 499-514.

Miller, L. S., Wasserman, G. A., Neugebauer, R., Gorman-Smith, D., \& Kamboukos, D. (1999). Witnessed community violence and antisocial behavior in high-risk urban boys. Journal of Clinical Child Psychology, 28, 2-11.

Muller, R. T., Goebel-Fabbri, A. E., Diamond, T., \& Dinklage, D. (2000). Social support and the relationship between family and community violence exposure and psychopathology among high risk adolescents. Child Abuse \& Neglect, 24(4), 449-464.

National Injury Mortality Surveillance System-Medical Research Council-University of South Africa (2010). Annual Report 2010. University of South Africa: Institute for Social and Health Sciences.

Oskin, D. L. (August, 1996). Impact of community violence exposure on children's hope. Paper presented at the Annual Meeting of the American Psychological Association: Canada.

Pastore, D. R., Fisher, M., \& Friedman, S. B. (1996). Violence and mental health problems among urban high school students. Journal of Adolescent Health, 18, 320-324.

Pollard, E. L., \& Lee, P. D. (2003). Child well-being: a systematic review of the literature. Social Indicators Research, 61(1), 59-78.

Pollard, E. L., \& Rosenberg, M. L. (2003). The strength based approach to child wellbeing: Let's begin with the end in mind. In M. H. Bornstein, L. Davidson, C. L. M. Keyes, \& K. A. Moore (Eds.), Well-being: Positive development across the life course (pp. 13-21). New Jersey: Laurence Earlbaum.

Ravens-Sieberer, U., Gosch, A., Rajmil, L, Erhart, M., Bruil, J. Duer, W., Auquier, P., Power, M., Abel, T., Czemy, L., Mazur, J., Czimbalmos, A., Tountas, Y., Hagquist, C., \& Kilroe, J. and the European KIDSCREEN Group. (2008). KIDSCREEN-52 quality of life measure for children and adolescents: Psychometric results from a crosscultural survey in 13 European countries. Value Health, 11, 645- 658.

Raviv, A., Raviv, A., Shimoni, H., Fox, N. A., \& Leavitt, L. A. (1999). Children's self-report of exposure to violence and its relation to emotional distress. Journal of Applied Developmental Psychology, 20(2), 337-353. 
Robitail, S., Simeoni, M., Erhart, M., Ravens-Sieberer, U., Bruil, J., Anquier, P., et al. (2006). Validation of the European proxy KIDSCREEN-52 pilot test health-related quality of life questionnaire: First results. Journal of Adolescent Health, 39, 596e1$596 \mathrm{e} 10$.

Rosario, M., Salzinger, S., Feldman, R. S., \& Ng-Mak, D. S. (2007). Intervening processes between youth's exposure to community violence and internalizing symptoms over time: the roles of social support and coping. American Journal of Community Psychology, 41(1, 2), 43-62.

Salzinger, S., Feldmana, R. S., Stockhammer, T., \& Hood, J. (2002). An ecological framework for understanding risk for exposure to community violence and the effects of exposure on children and adolescents. Aggression and Violent Behavior, $7,423-451$.

Savahl, S. (2010). Ideological constructions of childhood. Unpublished Doctoral Dissertation. University of the Western Cape: Bellville, South Africa.

Sawyer, W., Singh, W., Michael, C., Downes, T., Johnston, C., \& Whitton, D. (2007). Robust hope and teacher education policy. Asia-Pacific Journal of Teacher Education, 35(3), 227-242.

Schwab-Stone, M., Ayers, T. S., Kasprow, W., Voyce, C., Barone, C., Shriver, T., et al. (1995). No safe haven: a study of violence exposure in an urban community. Journal of the American Academy of Child and Adolescent Psychiatry, 34, 13431352.

Schwab-Stone, M., Chen, C., Greenberger, E., Silver, D., Lichtman, J., \& Voyce, C. (1999). No safe haven II: the effects of violence exposure on urban youth. Journal of the American Academy of Child and Adolescent Psychiatry, 38, 359-367.

Schwartz, D., \& Proctor, L. J. (2000). Community violence exposure and children's social adjustment in the school peer group: The mediating roles of emotion regulation and social cognition. Journal of Consulting and Clinical Psychology, 68(4), 670683.

September, R., \& Savahl, S. (2009). Children's perspectives of child well-being. The Social Work Practitioner Researcher, 21(1), 23-40.

Singer, M. I., Anglin, T. M., Song, L., \& Lunghoter, L. (1995). Adolescents' exposure to violence the association of psychological trauma. Journal of the American Medical Association, 273, 477-482.

Singer, M. I., Miller, D. B., Guo, S., Flannery, D. J., Frierson, T., \& Slovak, K. (1999). Contributors to violent behaviour among elementary and middle school children. Pediatrics, 104, 878-884.

Singh, M., \& Sawyer, W. (2008). Democracy and robust hope: Queensland's education and training reforms for the future. Education, Citizenship and Social Justice, 3(3), 223-237.

Snyder, C. R. (2002). Hope theory: rainbows in the mind. Psychological Inquiry, 13(4), 249-275.

Snyder, C. R., Hoza, B., Pelham, W. E., Rapoff, M., Ware, L., Danovsky, M., et al. (1997). The development and validation of the children's hope scale. Journal of Pediatric Psychology, 22(3), 399-421.

South African Police Service (2009). Crime Situation in South Africa. www.saps.gov.za. South African Police Service (2010). Crime Situation in South Africa. www.saps.gov.za. 
Sussman, S., Simon, T. R., Dent, C. W., Steinberg, J. M., \& Stacey, A. W. (1999). One-year prediction of violence perpetration among high-risk youth. American Journal of Health Behavior, 23, 332-344.

Ungar, M., \& Perry, B. D. (2012). Violence, trauma, and resilience. In R. Alaggia \& C. Vine (Eds.), Cruel but not unusual: Violence in Canadian families (2nd ed.). Canada: Wilfrid Laurier University Press.

United Nation Children's Fund (2009). South Africa Country Profile. Retrieved 19 May 2011, from http://www.unicef.org/southafrica/SAF_children_profile1109.pdf. 